\title{
BUILDING INFORMATION MODELING POTENTIAL FOR AN ENHANCED REAL ESTATE VALUATION APPROACH BASED ON THE HEDONIC METHOD
}

\author{
SIHAM EL YAMANI, MOHAMED ETTARID \& RAFIKA HAJJI \\ College of Geomatic Sciences and Surveying Engineering, IAV Hassan II Rabat, Morocco
}

\begin{abstract}
Housing valuation is a process of determining an accurate estimate of the market price of a property. Current methods and tools are mainly based on sales prices comparison with recent transactions, which is the major method applied in the taxation and cadastre services in Morocco. However, housing properties are in general heterogenous and unique in their shapes, construction materials, orientation, location and other environmental factors. These parameters are taken into consideration by the hedonic pricing method. Many of the researches about housing valuation are based on the geographical location as the main spatial factor affecting the property value. 2D GIS (Geographic Information System) applications used in this respect are limited in terms of communicating efficiently the complexity of a 3D building structure and modeling accurately environmental factors. Such factors could only be considered through 3D modeling and building information modeling (BIM). In this paper, we will try, through a brief review, to point out the weaknesses and drawbacks of the conventional valuation methods. Then, we will demonstrate the BIM potential in real valuation as an emerging technology and process used to mainly improve the housing valuation system based on the hedonic approach. Many studies are, nowadays, widely exploring the use of BIM in the building cost estimation, but this is an embryonic area of research in real estate valuation system. Therefore, this paper examines also the first methodological guidelines for an advanced housing valuation approach by implementing a BIM prototype based on the hedonic pricing method.
\end{abstract}

Keywords: BIM, housing valuation, cost estimation, real estate valuation, hedonic method.

\section{INTRODUCTION}

Housing market becomes a major economic issue of our times, that is tackled by many challenges such as unaffordability, unsustainability, speculation etc. Nowadays, seeking for the best housing offer which combines environment quality and indoors properties at an affordable price, becomes a difficult task. A housing valuation exercise is basically conducted by different players which include real estate agents, appraisers, mortgage lenders, property developers, among others [1].

The estimation of a property value usually applies both mathematical and computational approaches/methods which have been classified into traditional and advanced methods [1]. Researchers have argued that the traditional real estate valuation methods are mainly inaccurate and subjective [2]. While, advanced methods have demonstrated an enhanced property valuation estimate [1].

In a Moroccan context, where the regulation of real estate valuation and structuring of the real estate market is in progress, the efforts made, in terms of creating real estate observatories for better transparency of the local market and the introduction of a real estate tax referential by the General Tax Direction, remain mostly insufficient initiatives. Indeed, the lack of legislation and transparency of the real estate market (speculation) and the difficulty of accessing reliable and recent real estate data remain the main obstacles to effective real estate valuation. Fig. 1 shows an extract of maps representing the tax reference system applied by region. 


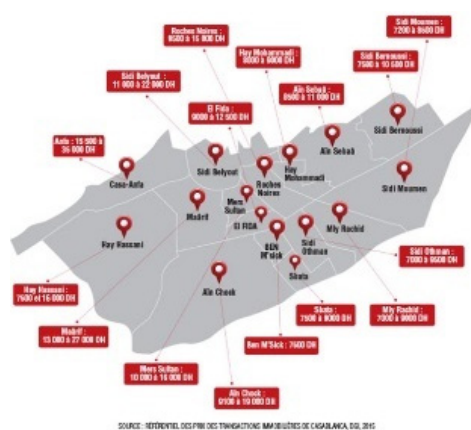

(a)

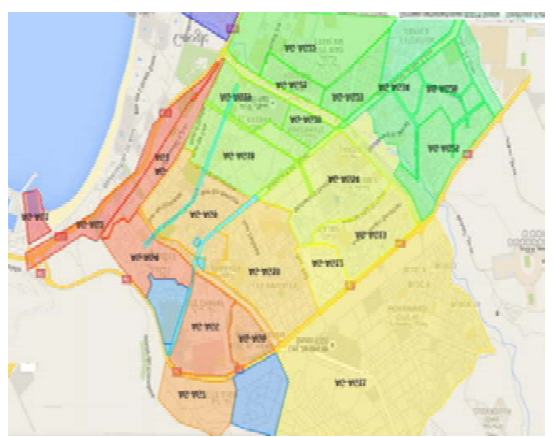

(b)

Figure 1: (a) Moroccan Tax reference system, Casablanca city, 2016; (b) Updated taxation and cadastral zoning, Casablanca city, 2019. (Source: Real Estate in Morocco [3].)

Several methods for real estate valuation exist in the literature. These methods can be grouped into traditional and advanced ones. Some examples of the traditional methods are: Regression models, Comparable method, Cost method, Income method, profit and contractor's method. Some of the advanced methods are Artificial neural networks, hedonic pricing method, spatial analysis methods, fuzzy logic [4].

The reality is $3 \mathrm{D}$ in nature. Hence, real estate valuation of a property should be performed in a $3 \mathrm{D}$ space. In fact, the value is the association of intrinsic parameters which are associated to the property as a $3 \mathrm{D}$ object and extrinsic parameters related to the $3 \mathrm{D}$ environment. Thus, real estate valuation should benefit from 3D technical achievements in BIM technologies. The use of BIM modelling approach is intended to refine the real estate valuation by the integration of internal parameters specific to each building element as well as the accurate quantities take off and the global construction's cost.

A BIM includes the geometry, the topology and the characteristics of building elements: cost estimates, material inventories and project schedule [5]. BIM model is so the rich information available through BIM model can be managed and used for advanced analysis in real estate valuation, such as using BIM for quantity take-off in cost approach [6] and simulating the impact of lightening, ventilation and noise propagation on the building model.

This paper aims to demonstrate the BIM potential in real estate valuation as an emerging technology and process used to improve the housing valuation system. Among available methods, we consider that the hedonic method is the most suitable for BIM integration. Many studies are, nowadays, widely exploring the use of BIM in the building cost estimation, but this is an embryonic area of research in real estate valuation system. Therefore, this paper examines also the first methodological guidelines for an advanced housing valuation approach by implementing a BIM prototype based on the hedonic pricing method.

\section{REAL ESTATE VALUATION METHODS}

Here, we present an overview of some traditional and advanced methods of real estate valuation. We focus on the hedonic pricing method as the basic method of our approach.

\subsection{Traditional methods}

The traditional methods of real estate valuation are described as methods analyzing the market value which is in general guided by the valuer interpretation. They are described as 
traditional because the estimation of the property value is based on classical techniques [1]. There are three valuation approaches based on the market analysis: 1. Comparative method (market approach); 2. Income method (capitalization) and 3. Cost method (replacement cost).

\subsubsection{Comparative method}

The wildly used method is the comparative approach. It is based on comparing the property price with many houses, sold recently, and providing comparable properties (physical, environmental) for the same economic area [1].

However, properties are unique, and many dissimilarities are observed in term of location, shape, orientation and physical compounds, so practically, there no identical comparative criteria [7]. In some cases, the first determination is adjusted after analyzing the market [8]. The price achieved from this comparative exercise represents an estimated market value also called a market approach [9].

The main property value relies on observing the seller and the buyer behavior without considering the cost of the construction operation which is an essential factor especially for the future building operations. Hence, when comparing the property with existing similar ones, the value relies strongly on an existing observed market prices, which is barely close to the real value [10].

According to this method, the final adjusted comparative value depends on data quality and availability which is rarely justified in the market [11]. However, this approach can be practical when a large database of qualified comparatives is provided, so the value determination is based on an objective process. Unfortunately, the problem of data inaccessibility is frequent. As a result, the method is inaccurate, and the resulting value is timeless. That is why valuers use subjective way for estimating the final property value. Due to these limitations, researchers tend to improve the valuation methods by integrating spatial modelling and BIM technologies with many factors defining the estimated property [12].

\subsubsection{Income method}

The second income method is like the comparative one in a sense that housing value is also based on the market observation. The property income is determined by comparing similar properties located in the same area to estimate operating income [13]. There are two ways of using the income approach: the simpler direct capitalization approach and the more advanced discounted cash flow method.

Contrarily to the capitalization method, the advanced method calculates the present value dependently to what future cash flows the property is expected to generate [14]. This approach is criticized for the same limits the comparative ones have. Because of the market non-transparency, the determination of the value-based income approach is also inaccurate and timeless.

\subsubsection{Cost method}

The cost method, called also the contractor's method, estimates the property value based on the building replacement cost including the appropriate depreciation. This approach is used especially if there are no similar properties to the appraised one. It's also particularly efficient for the insurance building estimation in case of a building being destroyed [13].

\subsection{Advanced methods}

Advanced methods are based on mathematical and modelling approaches [1]:

1. Artificial neural networks (ANNs); 
2. Hedonic pricing method;

3. Spatial analysis methods;

4. Fuzzy logic;

5. Autoregressive integrated moving average (ARIMA).

\subsection{Hedonic pricing method}

As a first definition, the hedonic pricing method is a statistical method based on multiple factor regression models that gives a clear answer to what a price a person can give to buy a property. The model relates the dependent variable i.e. the sales price with all variables of interest as explanatory variables - based on quantity and quality attributes of a large sample of similar properties. The samples are often selected using a combination of geographic distances as well as key attribute ranges such as size [7].

The basic mathematic formula is defined by Miller and Geltner [10] as:

$$
\text { Sale Price }=a+b 1(\text { Building size })+b 2(\text { Lot Size })+.+b n(x)+\text { residual },
$$

where:

$\mathrm{a}=$ is the constant term such as the land value. It might not be essential to have constant term unless the analyst is sure of omitting a key and stable influence such as land.

$\mathrm{b}=$ the regression coefficient, which is the estimate of the influence of variable $\mathrm{x}$ on value $\mathrm{c}=$ explanatory variables from each observation such as building size, lot size, and age, as shown above. Other variables could be used such as the number of bedrooms or bathroom. $\mathrm{n}=$ this represents other regression coefficients.

residual $=$ the average unexplained portion of selling prices for the sample of homes used in the estimation procedure.

According to the equation, the estimation of value comes through the estimation of the price function of all the property factors. In fact, the relevant factors affecting the property price are included event the extrinsic one [7]:

$$
\text { Price }=\mathrm{f}(\text { lightening, accessibility, noise propagation etc.), }
$$

where the determination of the property value comes from the estimation of some property factors [7], such as the building size, the lot size, the age, etc. The method is extensible to other external factors jugged relevant by the valuer. However, the advanced hedonic pricing method uses the geospatial modelling of many variables affecting the property value [15] and the main valuation is concluded by the multicriteria analysis [16]. The main limits of using the hedonic approach is the lack of price information and unavailable comparatives of the property attributes.

Although, the advanced hedonic method remains inaccurate without integrating 3D dimension. In fact, the main properties factors impacting the value depend also on elevation views, 3D geometry, orientation and the 3D location. For example, an apartment in the first floor isn't affected by the daylight factor in the same way as a one in the last floor [17]. Hence, the hedonic method needs to be enhanced in order to consider the real estate valuation in a 3D environment where houses are represented as 3D geometric and semantic objects.

Several researchers have addressed the determination impact factors of the housing value: Mccluskey [18] studied the application of spatially derived location factors within a GIS environment. Zhang et al. [19] have used 3D GIS to model the sunlight factor for real estate valuation. Cohen and Coughlin [20] proposed a framework for improving hedonic pricing method accuracy by introducing 3D Terrestrial Laser Scanning technology. Helbich et al. [21] addressed noise spatial modelling, while Des Rosiers et al. [22] investigate the analytical 
potential of factor analysis for sorting out neighborhood and accessibility factors in hedonic modelling using a simulation procedure that combines GIS technology and spatial statistics.

\section{BIM POTENTIAL FOR REAL ESTATE VALUATION}

In this section, we try to highlight the potential of BIM in real estate valuation. First, we give a general overview about BIM. Then, we analyze some examples of indoor factors simulation based on BIM models. Finally, we expose some reflections and first guidelines of our approach based on the integration of BIM and the hedonic pricing method.

\subsection{BIM overview}

Nowadays, numerous intelligent models and methods are improving the way building analysis are performed. Building information modelling (BIM) has proven to be one of the major innovations in the building industry. By offering a rich 3D model with geometric, topologic and functional characteristics of the building at the conceptual design phase, opportunities to simulate some parameters related to different domains (energy, noise, property valuation, ...) are improved [17].

BIM refers to two distinct contexts: as a product and as process. As a process, BIM is used to create, manage, derive and share building information among different actors involved in the building development process in order to facilitate collaboration and communication among them [23]. Consequently, the result of the BIM process is a BIM product which includes 3D digital spatial information as well as semantic information about a building to support decision making throughout its lifecycle [24]-[27].

The common standard Industrial Foundation Classes (IFC) was developed as a reference model for BIM models in the building industry. IFC was initiated with the idea of archiving the details of a building project throughout its life cycle. More fundamentally, it is a shared data model. Besides representing building geometric and topologic components, IFC also supports advanced processes and analyses based on the spatial relationships between these components. The IFC building model is defined according to the specifications made by International Alliance of Operability (IAI) and International Standards Organization (ISO) in the IFC standard documentation [28].

\subsection{Building cost estimation (5D BIM)}

The process of cost-estimating is strongly related to the take-off quantity. A well-detailed take-off can make cost-estimating more accurate, faster and requiring less interventions.

In traditional design work, accurate cost-estimating is only possible after presenting the documentation, when the exact amounts of materials and labor are available [29]. However, with BIM methods, such estimation can be available at an early stage of building lifecycle and updated after any changes.

Cost can be estimated in various ways and for different purposes during the whole building life cycle from design stage of construction projects until the facility management. In the early design stages, cost must be evaluated to study the project's feasibility and to make a reasonable decision. These early cost estimates are usually made without much information on the project and rely mostly on the designers' experience. A common quick estimation method is to use a per square meter cost ratio (building gross area). For stakeholders who often have a limited range of house typologies, such approximations can be provided based on comparing past project's cost estimation [30]. Fig. 2 shows the general process of the cost estimation method based on BIM. 


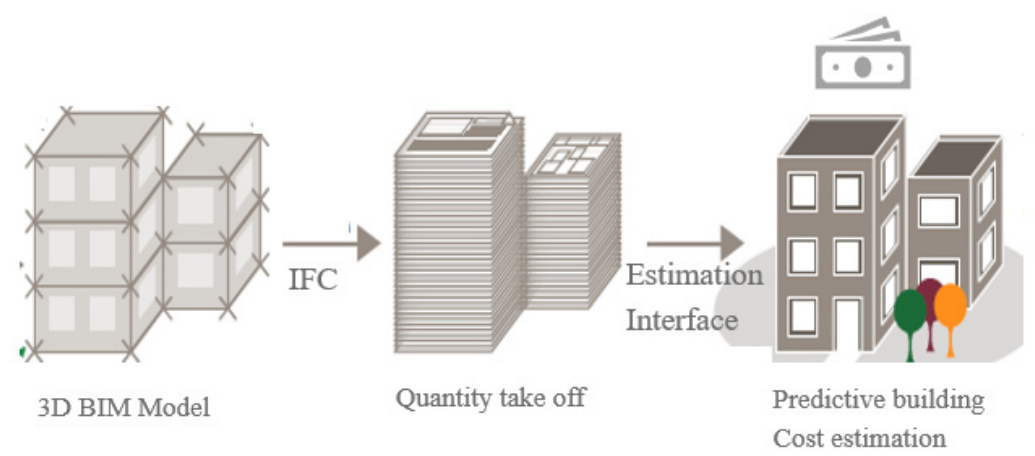

Figure 2: BIM cost estimation method.

More advanced techniques that use additional dimension information have been developed. Cost estimation method based on all building component surfaces that uses a specific weighting for each type of surface depending on its relative cost (i.e. a basement would receive a higher weighting than a wall because of excavation cost [29]. One of the most useful tasks that can be automated through the BIM use is the Quantity Take Off application. A BIM based the Quantity Take Off is supposed to provide simpler, more detailed and accurate cost estimation of the project, so reducing time and expenses [30].

There are a variety of ways of getting quantities and material definitions out of a building information model into a cost estimating system. Broad categories of integration approaches include [31]: Application Programming Interface (API) to commercially available estimating programs from vendors (ex. COST); ODBC connection to estimating programs such as CostX ODBC is a tried and true standard, useful for integrating data-centric applications like specification management and cost estimating with building information modeling. A part of the integration includes a reconstitution of the building data within the costing solution; linking cost geometry, attributes, and pricing; Output to Excel: in comparison to the approaches outlined above, quantity take offs done within Revit and output to a Microsoft Excel program may seem tough, but the simplicity and control is perfectly suited in some costing workflows.

Recently, several BIM-based cost estimation software programs have been developed to improve the efficiency of estimators. Widely known as 'BIM-based cost estimation', programs include the following: Innovaya Visual Estimating, Vico Estimator 2009, Tokmo Production System, Success Design Exchange, Timberline Extended and WinEst Design Estimation Pro. However, and plugins such as CostX, widely used software of this type in Australia [32] the combination of different software types is in general hardly applicable within interoperability [30], [33].

\subsection{BIM for indoors factors}

There are several property characteristics that are integrated in the valuation method [34]. Basically, the building situation, area and physical attributes (number of rooms etc.) are the main used characteristics [35]. Another study investigates noise propagation, accessibility and building orientation as an impacting factor for housing estimation. In fact, other research's focus on modelling the outdoor environment and estimates as there impacts on the 
property value [36]. These factors are hardly modelized and their impact on the final property value is barely noticed accurately.

This section is presenting the main indoors factors affecting the property value and how they can be modelized accurately by using the building information modelling technology and other connected software's and plugins.

BIM provides a 3D model which is used by various simulation tools to extract the building impacting factors, especially the ones affecting the indoor environment (orientation, daylighting, ventilation etc.). These tools allow predicting the future housing valuation by the contactors and different stakeholders and also the real estate appraisal to make the right decisions at an early design phase [37]. Table 1 presents the variables associated to each factor and the corresponding data sources in the building model with the potential software [12], [38], [39].

BIM sunlight duration analysis uses professional software based on BIM model (Revit, Insight plugin) to simulate the sun movement in a day and result in a grid with sunlight hours on the surface of buildings. BIM indoor/outdoor ventilation analysis based on CFD (Computational Fluid Dynamics) analysis model, and 3D community building models to simulate the indoor environment ventilation or surrounding environment ventilation. While

Table 1: Indoors impact factors.

\begin{tabular}{|c|c|c|c|}
\hline Factors & Variables & Relevant data/source & Potential software \\
\hline $\begin{array}{l}\text { Building } \\
\text { components }\end{array}$ & $\begin{array}{l}\text { Area, floor level, } \\
\text { number of units, } \\
\text { materials, } \\
\text { heating system. }\end{array}$ & $\begin{array}{l}\text { - BIM model } \\
\text { (conception plans) }\end{array}$ & BIM Revit \\
\hline $\begin{array}{l}\text { Building } \\
\text { elements }\end{array}$ & $\begin{array}{l}\text { Wall, roof, } \\
\text { stairs/elevator, } \\
\text { materiel }\end{array}$ & $\begin{array}{l}\text { - BIM model } \\
\text { (conception plans) } \\
\text { - IFC standard }\end{array}$ & BIM Revit \\
\hline $\begin{array}{l}\text { Cost } \\
\text { information }\end{array}$ & Building cost & $\begin{array}{l}\text { - Building elements } \\
\text { - Building components } \\
\text { - Quantities Take-off } \\
\text { - Fabrication cost per } \mathrm{m}^{2}\end{array}$ & $\begin{array}{l}\text { - BIM Revit } \\
\text { - Green Building } \\
\text { Studio }\end{array}$ \\
\hline \multirow{3}{*}{$\begin{array}{l}\text { Indoor } \\
\text { environment }\end{array}$} & $\begin{array}{l}\text { Indoor daylight } \\
\text { Shading/lightning } \\
\text { Sunlight duration }\end{array}$ & $\begin{array}{l}\text { - BIM model } \\
\text { - Weather, Location } \\
\text { - Orientation } \\
\text { - Sunshine time } \\
\text { - Façade materials } \\
\end{array}$ & $\begin{array}{l}\text { - Insight plugins } \\
\text { - } 360 \text { rendering and } \\
\text { lightning analysis }\end{array}$ \\
\hline & $\begin{array}{l}\text { Indoor/ } \\
\text { Outdoor } \\
\text { Ventilation } \\
\text { (Air flow) }\end{array}$ & $\begin{array}{l}\text { - Building geometry } \\
\text { - Weather/Materials } \\
\text { (wind speeds) } \\
\text { - Orientation } \\
\text { - Thermal comfort } \\
\end{array}$ & $\begin{array}{l}\text { - Green Building } \\
\text { Studio } \\
\text { - Autodesk } \\
\text { flow design } \\
\text { - Autodesk CFD }\end{array}$ \\
\hline & Noise propagation & $\begin{array}{l}\text { - Materials } \\
\text { - Building Volume } \\
\text { - Absorbance coefficient }\end{array}$ & - Rhino/Revit \\
\hline
\end{tabular}




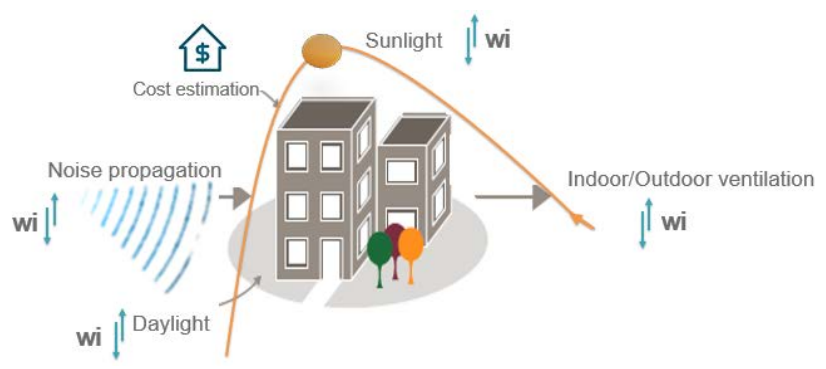

Figure 3: Weighted impact factors (wi) on the final value.

BIM noise propagation analysis determines the decibel value by professional analysis model. BIM indoor daylight analysis is based on the detailed 3D building model by considering the different construction materials to calculate the daylight factor under different sunlight conditions [36].

Modeling indoor factors provides a visualization of theirs impact on the $3 \mathrm{D}$ building construction cost. In purpose to estimate the final adjusted valuation depending on the weighted impact of each factors (Fig. 3), the performance of factors is required.

BIM also provide building performance analysis and energy simulation's plugins and programs. In fact, the BIM software (Revit) integrates daylighting, ventilation and energy (Computational Fluid Dynamic) performances simulations [40]. These simulation tools can analyze and improve building environmental performances throughout the design development stages. Thus, the benefits of BIM for indoors factors modelling had been wildly investigated by researchers. For instance, the BIM model can be used for estimating the indoors factors value and its impact on the property value [41].

BIM-based factors simulation is the most time and cost saving method that allows testing on variety of design configurations. It allows study of building performance from the design development stage until post occupancy evaluation. A BIM model can be employed for various simulations.

Autodesk Revit offers a form of simplified energy performance analysis (Green Building Studio), estimating whole building performance. This is useful at early stages of design for comparison between options, but later where calibration of operating schedules and definition of equipment loads is essential; a validated analysis tool is necessary [33].

\subsection{BIM based hedonic approach for housing valuation}

In this section, a first methodological guidelines for our prototype are presented. The proposed method (Fig. 4) is based on integrating the housing 3D model into the BIM software with the different data input required for an accurate 3D simulation of the different relevant factors for the estimation of the property value. In order to do that, the first step consists of the BIM modelling from the design data project which will be structured according the specifications of the IFC format. The BIM model will provide geometric and semantic information and some characteristics such as the building materials of all compounds.

Then, an enhanced housing valuation method is introduced as the combination of the advanced hedonic pricing method and the building information modelling. At this stage, the first hedonic variable is calculated based on the building cost estimation. Thus, the hedonic factors values, presented in Section 3.2: BIM for indoors factors, are determined. 


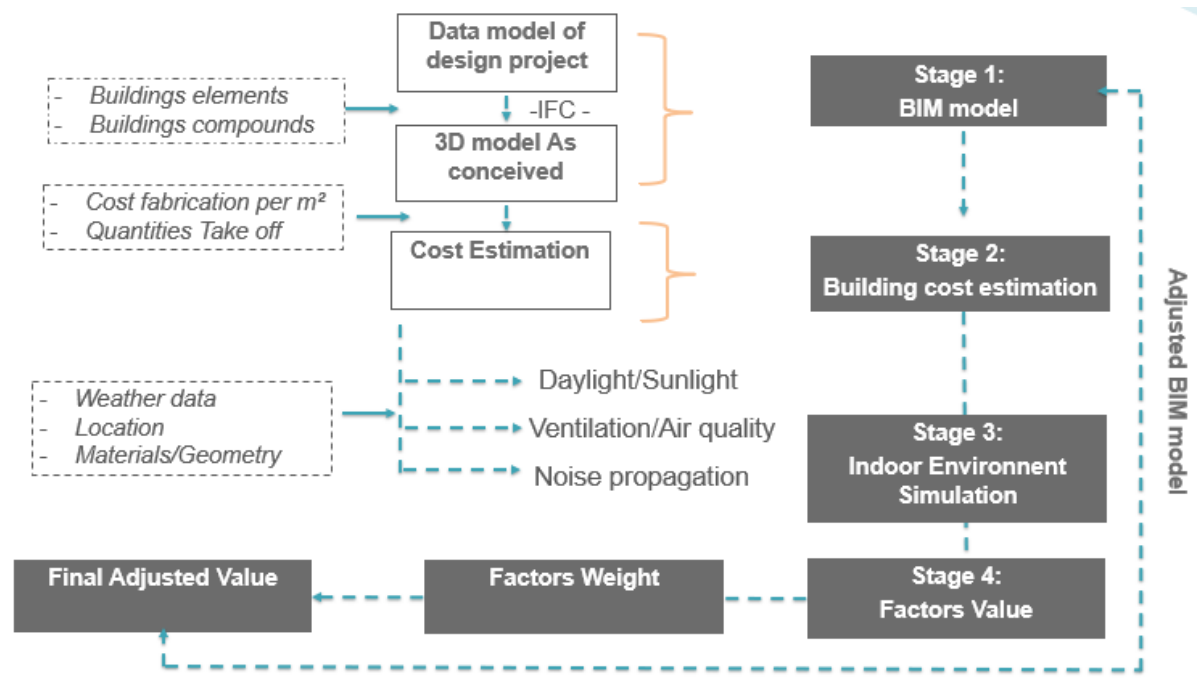

Figure 4: Guidelines for the proposed approach.

Table 2: Performance analysis based on the value of daylight factor. (Source: $Y u$, 2014 [12].)

\begin{tabular}{|c|c|}
\hline Grade & Description (average value of daylight factor c) \\
\hline 0 & $\mathrm{C}<1 \%$ \\
\hline 1 & $1 \% \leq \mathrm{c}<2 \%$ \\
\hline 2 & $2 \% \leq \mathrm{c}<3 \%$ \\
\hline 3 & $3 \% \leq \mathrm{c}<4 \%$ \\
\hline 4 & $\mathrm{C} \geq 4 \%$ \\
\hline
\end{tabular}

These factors are analyzed, and the property value is estimated by weighting each factor. The weighting valuation can be conducted based on national/international performance standards. An example of this valuation according to standards for the daylight factor is presented in Table 2. However, first housing valuation determination is intended to be adjusted in case of any changes that could affect the BIM model (i.e. change of materials due to the budget's limits). Therefore, the weight of some factors can be impacted, which makes the final value estimated through an iterative process.

\section{DISCUSSION}

As previously highlighted in this paper, Moroccan housing market is facing a challenging issue in terms of speculation, transparency, unaffordability and unsustainability etc. In recent years, several attempts are made to overcome those struggles. The General Taxation Administration and the cadastre launched a property price reference guide in order to regulate the real estate market behavior by providing a basis for real estate valuation. However, this reference guide is based on a classical comparative approach which is limited in terms of data efficiency as reviewed in Section 2. So, the efforts made remain insufficient and the adoption of a new enhanced approach is a crucial need. 
In Morocco, the adoption of BIM for new construction projects is a growing trend. Several leading projects are adopting BIM as a new technology for modeling and storing 3D buildings information, mainly in the design and construction phases. Therefore, BIM potential could serve as a support for real estate valuation methods. This is a way to take advantage from BIM potential in modeling and simulating real estate from intrinsic and extrinsic factors affecting the indoor environment.

We can so argue that introducing such a potential method to the market is feasible but still need time and tools to be adopted. Some of the key guidelines that will enable the implementation and the adoption of such BIM-based approach are:

- Presenting significant results that demonstrate the efficiency and the enhanced property valuation as a proof of concept;

- Feasibility to introduce such a method to real estate appraisers as a potential to their professional prestation's;

- Developing interoperable tools and frameworks to implement this new approach;

- Making a comparison between the BIM-based real estate valuation method and the traditional ones.

- Raising the awareness of decision makers to adopt such a changing paradigm approach;

- Providing specific "BIM-real estate valuation" training and education programs delivered by academic's institutions or professional associations.

\section{CONCLUSION}

Building information modelling is now recognized as a challenging technology in the building industry. Real estate valuation methods, mainly based on classical tools, should benefit from BIM achievements in order to make simulation of factors more consistent and accurate. However, the integration of BIM in real estate valuation is a challenging issue. We presented in this paper, our first reflections about a new approach based on the integration of BIM and the hedonic pricing method. We also proposed a conceptual workflow to deal with this integration.

However, we argue that work is needed to deal with some conceptual issues such as the extension of the IFC format to respond to the real estate valuation domain, as well as technical issues related to the implementation of the BIM model, the interoperability between BIM and some external simulation tools (i.e. for energy analysis) and the simulation process according the guidelines of existing performance analysis methods.

Our future work will focus on testing the proposed workflow through a case study in order to demonstrate the potential of the BIM and to validate and refine the methodology of the approach. Another extension of this work should consider the environment of the building as relevant for real estate valuation. Thanks to 3D GIS evolution, a BIM model can be integrated to a 3D GIS prototype in order to add some extrinsic environmental factors and all data about the quality of life. This will be led to a refined property valuation method.

\section{REFERENCES}

[1] Pagourtzi, E. et al., Real estate appraisal: A review of valuation methods. J Prop Invest Financ, 21, pp. 383-401, 2003.

[2] Zurada, J.M., Levitan, A.S. \& Guan, J., Non-conventional approaches to property value assessment. J Appl Bus Res, 22, pp. 1-14, 2006.

[3] Moroccan taxation reference, Casablanca city, 2016, Blog, Online. http://infoimmobilier-maroc.blogspot.com/2016/01/. 
[4] Chan, A.P.C. \& Abidoye, R.B., Advanced property valuation techniques and valuation accuracy: Deciphering the artificial neural network technique. Rel Int J Real Estate L Plan, 2, pp. 1-9, 2019.

[5] Azhar, S., Building information modeling (BIM): Trends, benefits, risks, challenges for the AEC Industry. Leadersh Manage Eng, 11, pp. 241-252, 2011.

[6] Cheng, J.C.P, Deng, Y. \& Du, Q., Mapping between BIM models and 3D Gis City models of different levels of detail. 13th Int Conf Constr Appl Virtual Real (CONVR 2013), London, United Kingdom, pp. 502-514, 2013.

[7] Adekunle, K., Patrick, A. \& Eke, O., A review of real estate valuation and optimal pricing techniques. Contribution/Originality, 4, pp. 1878-1893, 2014.

[8] Poursaeed, O., Matera, T. \& Belongie, S., Vision-based real estate price estimation. Mach Vis Appl, 29, pp. 667-676, 2018.

[9] Shapiro, E., Modern Methods of Valuation, London: Taylor and Francis, 2012.

[10] Miller, N.G. \& Geltner, D., Real estate principles for the new economy. J. Real Estate Lit, 12, pp. 407-409, 2004.

[11] Herber, W.C. \& Strachota, R.J., Real Estate Valuation and Division.

[12] Yu, H., Using 3D Geographic Information System to Improve Sales Comparison Approach for Real Estate Valuation, p. 7057, 2014.

[13] Yomralioglu, T. \& Nisanci, R., Nominal asset land valuation technique by GIS. Int Fed Surv Work week, 22-27 May 2004, pp. 1-9, 2004.

[14] Royal Institution of Chartered Surveyors, RICS Valuation - Professional Standards January 2014 RICS Valuation, p. 334, 2014.

[15] Lake, I.R. et al., Using gis and large-scale digital data to implement hedonic pricing studies. Int J Geogr Inf Sci, 14, pp. 521-541, 2000.

[16] Al-shalabi, M.A. et al., GIS Based multicriteria approaches to housing site suitability assessment. Shaping the Change, pp. 1-17, 2006.

[17] Amoruso, F.M., Dietrich, U. \& Schuetze, T., Integrated BIM-parametric workflowbased analysis of daylight improvement for sustainable renovation of an exemplary apartment in Seoul, Korea. Sustainability, 11, p. 2699, 2019.

[18] Mccluskey, W.J., Lamont, I. \& Deddis, W.G., The Application of Spatially Derived Location Factors within a Gis Environment, p. 11, 1993.

[19] Zhang, H. et al., The application of GIS 3D modeling and analysis technology in real estate mass appraisal - Taking landscape and sunlight factors as the example. Int Arch Photogramm Remote Sens Spat Inf Sci - ISPRS Arch, 40, pp. 363-367, 2014.

[20] Cohen, J.P. \& Coughlin, C.C., Spatial hedonic models of airport noise, proximity, an housing prices. J Reg Sci, 48, pp. 859-878, 2008.

[21] Helbich, M. et al., Boosting the predictive accuracy of urban hedonic house price models through airborne laser scanning. Comput Environ Urban Syst, 39, pp. 81-92, 2013.

[22] Des Rosiers, F., Thériault, M. \& Villeneuve, P.Y., Sorting out access and neighbourhood factors in hedonic price modelling. J Prop Invest Financ, 18, pp. 291$315,2000$.

[23] Eastman, C.M., BIM Handbook: A Guide to Building Information Modeling for Owners, Managers, Designers, Engineers and Contractors, Wiley, 2011.

[24] Dana, K. \& Smith, M.T., Building information modeling: A strategic implementation guide for architects, engineers, constructors, and real estate asset managers, KissLibrary, Affordable Ebooks.

[25] Isikdag, U. et al., Utilizing $3 D$ Building and $3 D$ Cadastre Geometries for Better Valuation of Existing Real Estate. 
[26] Atazadeh, B. et al., Building information modelling for high-rise land administration. Trans GIS, 21, pp. 91-113, 2017.

[27] Al-Shalabi, M.A. et al., GIS-based multicriteria approaches to site suitability analysis. XXII FIG Congr, pp. 1-17, 2006.

[28] Zhang, J. et al., No 主観的健康感を中心とした在宅高齢者における 健康関連指 標に関する共分散構造分析. J Real Estate Financ Econ, 10, pp. 331-341, 2018.

[29] Chardon, S. et al., Construction cost and energy performance of single family houses: From integrated design to automated optimization. Autom Constr, 70, pp. 1-13, 2016.

[30] Plebankiewicz, E., Zima, K. \& Skibniewski, M., Analysis of the first polish BIM-based cost estimation application. Procedia Eng, 123, pp. 405-414, 2015.

[31] Autodesk, Building information modeling and cost estimating. Autodesk, p. 8, 2007.

[32] Smith, P., Project cost management with 5D BIM. Procedia - Soc Behav Sci, 22, pp. 193-200, 2016.

[33] Gerrish, T., Exploring the effectiveness of BIM for energy performance management of non-domestic buildings, 2017, https://dspace.lboro.ac.uk/2134/25094.

[34] Rosen, S., Hedonic Prices and Implicit Markets: Product Differentiation in Pure Competition.

[35] Wyatt, P.J., The development of a GIS-based property information system for real estate valuation. Int J Geogr Inf Sci, 11, pp. 435-450, 1997.

[36] Liu, H.Y., Integrating geographic information and valuation modeling for real estate. Appraisal J., 78, pp. 370-378, 2016.

[37] Azhar, S., Khalfan, M. \& Maqsood, T., Building Information Modeling (BIM): Now and Beyond, Epub ahead of print, 2009. DOI: 10.5130/ajceb.v12i4.3032.

[38] Kirkegaard, P.H. \& Kamari, A., (eds), Building Information Modeling (BIM) for Indoor Environmental Performance Analysis, p. 86, 2017.

[39] Lim, Y.W., Building information modeling for indoor environmental performance analysis. Am J Environ Sci, 11, pp. 55-61, 2015.

[40] Azhar, S., Brown, J. \& Farooqui, R., BIM-based sustainability analysis: An evaluation of building performance analysis software. 45th ASC Annu Conf, pp. 1-4, 2009.

[41] Plebankiewicz, E., Zima, K. \& Skibniewski, M., Construction cost and time planning using BIM-based applications. Creat Constr Conf, pp. 537-545, 2015. 